\title{
Myoid Angioendothelioma: A Rare Benign Splenic Tumor
}

\author{
Vladimir Milosavljevic ${ }^{1} \mathbb{D}$, Boris Tadic $^{2}{ }^{\mathbb{D}}$, Mauricio Gonzalez-Urquijo ${ }^{3}$, Djordje Knezevic ${ }^{2}$, \\ Nikola Grubor² ${ }^{2}$
}

\author{
${ }^{1}$ Gracia Medica Polyclinic, Belgrade, Serbia \\ ${ }^{2}$ Department for HPB Surgery, Clinic for Digestive Surgery, Clinical Centre of Serbia, Belgrade, Serbia \\ ${ }^{3}$ Tecnologico de Monterrey, School of Medicine and Health Sciences, Mexico
}

A 54-year-old female was referred to our clinic for evaluation of an incidentally found splenic mass revealed during a routine abdominal ultrasound examination. The patient denied any abdominal trauma, complaints, or past surgical operations. His medical history was unremarkable. Baseline hematological and biochemical investigations as well as the tumor markers were all within the normal ranges. Magnetic resonance imaging demonstrated a hyperintense splenic lesion, of a total size of $5 \mathrm{~cm}$, which corresponded to the splenic tumor. As the nature of the splenic mass could not be precisely determined by preoperative assessments nor malignancy could be excluded, we opted for laparoscopic splenectomy. The surgery was completed without complications and the postoperative course was entirely uneventful. The patient was discharged from the clinic 4 days later. Written informed consent was obtained from the patient.

Twenty-one years after the first case of MAE was reported by Kraus and Dehner (1999), the small number of published papers makes it difficult to draw conclusions about this rare splenic entity. ${ }^{1}$ In most cases, MAE is clinically silent, but mild abdominal discomfort
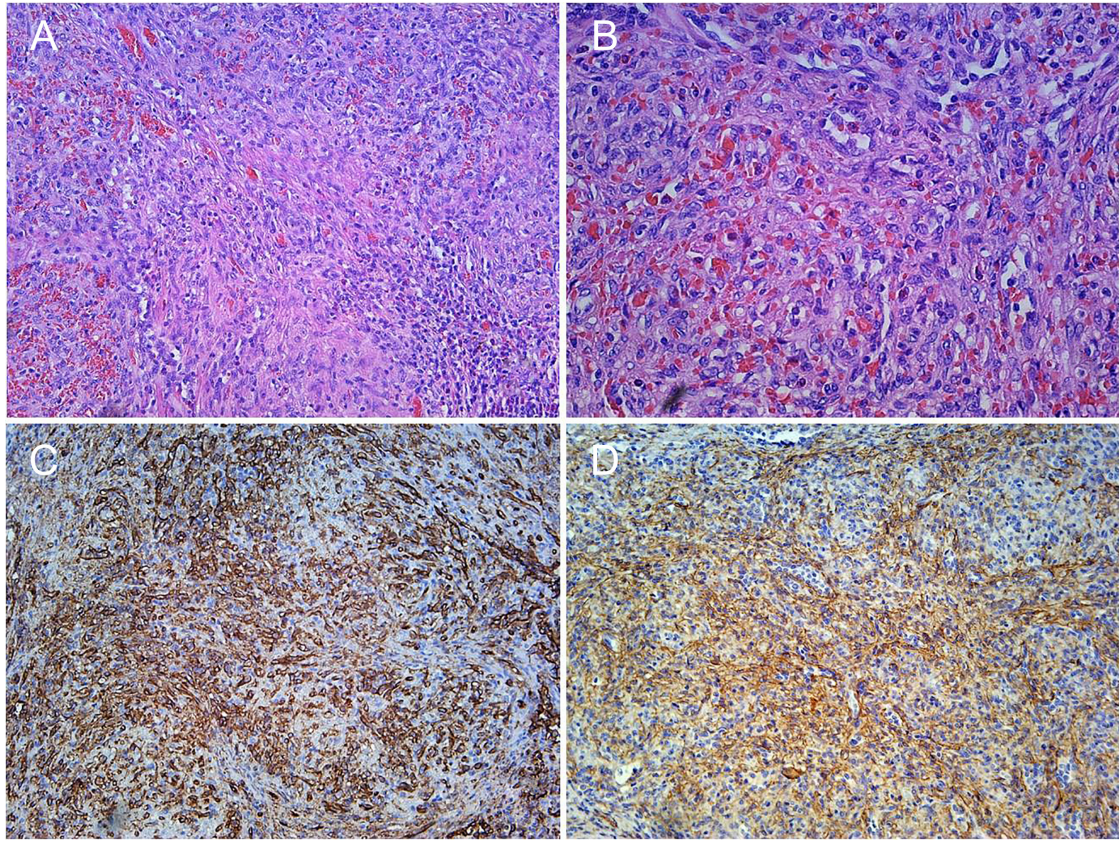

FIG. 1. A-D. Histomorphology with mesenchymal features (A-D): A)Histological presentation of vascular tumor with characteristic compact proliferation of vascular and stromal elements (H\&,Ex100), B) Sieve-like and focally dilated vessels, (H\&Ex200), C)Strong immunoexpression for CD34, (IHCx100), D) Immunopositivity for Smooth muscle actin in stromal cells, (IHCx100).

Address for Correspondence: Boris Tadic, Department for HPB Surgery, Clinic for Digestive Surgery, Clinical Centre of Serbia, Belgrade, Serbia e-mail: tadicboris@yahoo.com

Received: September 18, 2020 Accepted: January 17, $2021 \cdot$ DOI: 10.5152/balkanmedj.2021.20100

Available at www.balkanmedicaljournal.org

ORCID iDs of the authors: B.T. 0000-0001-5400-1015; N.G. 0000-0002-2354-7784; V.M. 0000-0002-6998-2116; D.K. 0000-0003-3703-6018; M.G.U. 0000-0001-5101-1541.

Cite this article as:

Milosavljevic V, Tadic B, Gonzalez-Urquijo M, Knezevic D, Grubor N. Myoid angioendothelioma: A rare benign splenic tumor. Balkan Med J. 2021 ; $38(3): 190-191$.

Copyright@Author(s) - Available online at http://balkanmedicaljournal.org/ 
may occur. ${ }^{2}$ It is usually found by coincidence as an incidental finding during imaging diagnostics due to some other medical condition. Despite the use of modern radiological imaging, radiological findings, which could help to unequivocally diagnose MAE, have not been defined so far. Primary neoplasms of the spleen, such as haemangioma, hamartoma, angiosarcoma, haemangiopericytoma, and haemangioendothelioma or metastatic disease, are common differentials. ${ }^{3}$ Some authors consider fine needle aspiration biopsy as a useful procedure to define the nature of splenic neoplasms, but apart from the possible splenic rupture and bleeding, the specimens in most cases may not be reliable. ${ }^{4,5}$

Myoid angioendothelioma of the spleen has an indolent course with a favorable prognosis. Disease recurrence has not been reported. Given that preoperative diagnostics is inconclusive, splenectomy, followed by histological and immunohistochemical analysis, is required to confirm the diagnosis.

Patient Consent for Publication: Written informed consent was obtained from the patient.
Author Contributions: Concept - V.M.; Design - B.T.; Supervision - V.M., M.G-U.; Data Collection and/or Processing - D.K.; Literature Review - M.G-U.; Writing - V.M., N.G..; Critical Review - B.T., D.K.

Conflict of Interest: The authors have no conflicts of interest to declare.

Funding: The authors declared that this study has received no financial support.

\section{REFERENCES}

1. Kraus MD, Dehner LP. Benign vascular neoplasms of the spleen with myoid and angioendotheliomatous features. Histopathology. 1999;35(4):328-336. [CrossRef]

2. Geramizadeh B, Anbardar M, Malekhosseini SA. Myoid angioendothelioma of the spleen: a rare case report and literature review. Iran J Med Sci. 2017;42(1):89-93.

3. Jang KY, Chung MJ, Moon WS, et al. Myoid angioendothelioma of the spleen mimicking metastatic disease in a patient with rectal cancer: a radiologic-pathologic correlation. Ann Diagn Pathol. 2013;17(1):108-112. [CrossRef]

4. Weinreb I, Bailey D, Battaglia D, Kennedy M, Perez-Ordoñez B. CD30 and EpsteinBarr virus RNA expression in sclerosing angiomatoid nodular transformation of spleen. Virchows Arch. 2007;451(1):73-79. [CrossRef]

5. Gonzalez-Urquijo M, Rodarte-Shade M, Gil-Galindo G. Splenic primary solid tumors: does a preoperative histopathology diagnosis really matter? Am Surg. 2021;87(2):316-320. [CrossRef] 